\title{
European analytical column number 49
}

\author{
Slavica Ražić ${ }^{1} \cdot$ Marcela A. Segundo $^{2} \cdot$ Martin Vogel $^{3}$
}

Accepted: 27 October 2021 / Published online: 4 November 2021

(c) Springer-Verlag GmbH Germany, part of Springer Nature 2021

\section{EuChems European Chemical Society} —Division of Analytical Chemistry__

The European Analytical Column is the voice of the Division of Analytical Chemistry (DAC) as a professional network of chemical societies and their members working in all fields of analytical sciences within the European Chemical Society (EuChemS). The strategy for 2021-2023 involves the promotion of analytical chemistry to a wider community, co-operation with other professional networks, and supporting members' activities, particularly through study groups and task forces. This year, we will focus on how our community has managed to adapt to teaching analytical chemistry during the pandemic. Please feel free to share your own experiences through our social media and networks!

Slavica Ražić

slavica.razic@pharmacy.bg.ac.rs

Marcela A. Segundo

msegundo@ff.up.pt

Martin Vogel

martin.vogel@uni-muenster.de

1 Department of Analytical Chemistry, Faculty of Pharmacy, University of Belgrade, Vojvode Stepe 450, 11222 Belgrade, Serbia

2 Department of Chemical Sciences, Faculty of Pharmacy, University of Porto, R Jorge Viterbo Ferreira, 228, 4050-313 Porto, Portugal

3 Institute for Inorganic and Analytical Chemistry, University of Münster, Corrensstraße, 28, 48149 Münster, Germany

\section{DAC-EuChemS activities}

One of the main activities of DAC-EuChemS is the promotion and organization of the Euroanalysis conference. Every two years, one of the participating scientific chemical societies will host Euroanalysis, with active involvement from local scientists in the organization. Euroanalysis XXI was scheduled for August 2021, but the pandemic prevented us from meeting in person as an analytical community this year. Instead, we met online last September for a webinar dedicated to our Awardees Prof. Aldo Roda (DAC-EuChemS Award) and Prof. Karen Faulds (Rober Kellner Lecture Award), who gifted us with two wonderful lectures, which can be seen at https://youtu.be/I2runlAeq5A, that were sponsored by Springer. Euroanalysis XXI is now rescheduled for 2023, and it will take place in Geneva, Switzerland, under the auspices of the Swiss Chemical Society (https:// www.euroanalysis2023.ch/), organized by Prof. Eric Bakker (University of Geneva), Dr. Marc Suter (EAWAG), Dr. Franka Kalman (HES Sion), and Dr. Bodo Hattendorf (ETH Zurich).

The study groups are also responsible for several ongoing activities of DAC-EuChemS. The topics addressed include "Bioanalytics", "Chemometrics", "Education", "Electroanalytical Chemistry", "History", "Nanoanalytics", "Quality Assurance", and "Sample Preparation". Please visit the DAC-EuChemS website for updated reports (https://www. euchems.eu/divisions/analytical-chemistry/) and contact the heads of the study groups for more information or to participate in their activities.

Lastly, one of DAC-EuChemS objectives is to support its delegates with the organization of local events open to the international community through dissemination of the event within the professional network, including online events. The steering committee of DAC-EuChemS is happy to receive input for additional activities. Feel free to contact one of the following people: Slavica Ražić, University of Belgrade, Serbia (Chair); Marcela Segundo, University of Porto, Portugal (Secretary); Jiří Barek, Charles University, Czech Republic (Treasurer); Charlotta Turner, Lund 
University, Sweden; Sibel A. Özkan, Ankara University, Turkey; Lutgarde Buydens, Radboud University, the Netherlands; and Martin Vogel, University of Münster, Germany.

\section{Teaching analytical chemistry during the pandemic: an enduring endeavour - but not in vain!}

When the coronavirus pandemic first hit many parts of the world in spring 2020, surely few of us imagined that its influence on our everyday lives would be that drastic, and, even worse, that enduring. It would be moot to enumerate once again what has been changing over the last 15 months or so. However, it is surely worth having a closer look at the dramatic changes in teaching (not only) of analytical chemistry that instructors all over the world have faced since 2020.

As social distancing was recognized as an early key measure to interrupt the spread of Covid-19, remote teaching was rapidly introduced wherever and whenever possible. This was - and still is - an endeavour for all of us teaching a subject, such as analytical chemistry, that is fundamentally dependent on experimental practice in the laboratory. While many instructors were thrown in at the deep end in early 2020 , many of them rapidly developed innovative and smart approaches to cope with the new challenges. The many experiences, lessons learned, and conclusions drawn by instructors are worth sharing with the analytical community as a whole.

In January 2021, the "ABCs of Education and Professional Development in Analytical Science" column started a series of articles featuring the teaching of analytical chemistry during the pandemic. The idea of this series is to support instructors all over the world in preparing their courses. Several articles on different aspects of remote teaching have been published to date, and will surely be inspiring for many readers and hopefully activate some of them to share their experiences and ideas by also publishing an article for the column.

For example, Emily Niemeyer and co-authors contributed a paper describing some hands-on laboratory experiments that students could complete while studying off campus [1]. In their paper, easy, remote laboratory experiments are described that are based on carbonate chemistry and that are used to deal with gravimetry and titrimetry, just to mention one example. Supplemental material is provided, allowing readers to implement the experiments described in their courses.

Another paper published in this special series by Elise Heiss and Susan Oxley describes the implementation of a flipped classroom approach for two different analytical chemistry courses [2]. While presenting their experiences with different aspects of flipped classrooms, personal reflections, and recommendations of best practices, the article may serve as an inspiration for readers when thinking about the different forms of remote learning (asynchronous, synchronous, as well as assessment).

All of us who have taught remotely during the last months have surely been faced with the question of how to enhance student engagement in their courses. Jill Venton and Rebecca Pompano provide many good ideas and answers to this question, while discussing active learning as a strategy [3]. The article is a valuable source of practical tips for student engagement and provides many answers to didactic questions arising from the current Zoom world.

Another paper dealing with the question of student interaction and student engagement has been contributed by Anna Cavinato and co-authors [4]. Based on their experiences, four instructors describe their views on engaging students in an online environment. The article will surely inspire readers through the authors' profound description of their experiences in different remote settings and their conclusions drawn thereof.

An aspect that has turned out to be even more crucial during the pandemic than in normal times is different access to technical infrastructure and financial resources. Vilmalí López-Mejías and co-authors from the University of Puerto Rico therefore describe their methods and experiences of remote teaching of analytical chemistry at an institution that, prior to the pandemic, had already been hit by, e.g., hurricanes and earthquakes [5]. The article is a good combination of showing different didactic approaches for remote learning in synchronous and in asynchronous modes and of presenting remote laboratory experiences to the readers. Supplemental material allows a deeper look into the functioning of the courses.

All these articles presented show that teaching during the pandemic has been - and still is - a challenge, and serving our students in the best way has become even more of an endeavour. However, the experiences and concepts developed will surely be not in vain, as many of them can be integrated into regular courses. Moreover, we are sure, we shall return to normal life - with many lessons learned from the pandemic.

We hope that this small survey of articles recently published in "ABCs of Education and Professional Development in Analytical Science" supports many readers while preparing and running their courses and stimulates them to share their experiences and concepts developed with colleagues in the field. 


\section{References}

1. Destino JF, Gross EM, Niemeyer ED, Petrovic SC. Anal Bioanal Chem. 2021;413:1237-44.

2. Heiss EM, Oxley SP. Anal Bioanal Chem. 2021;413:1245-50.

3. Venton BJ, Pompano RR. Anal Bioanal Chem. 2021;413:1507-12.

4. Cavinato AG, Hunter RA, Ott LS, Robinson JK. Anal Bioanal Chem. 2021;413:1513-20.
5. Morales-Cruz AL, Ortiz-Andrade BM, Del Pilar-Albaladejo J, Díaz-Vázquez LM, Rivera-González U, López-Mejías V. Anal Bioanal Chem. 2021;413:2845-53.

Publisher's note Springer Nature remains neutral with regard to jurisdictional claims in published maps and institutional affiliations. 